\title{
Urinary soluble alpha chain of the interleukin-2 receptor as a biomarker of active lupus nephritis in Egyptian children with juvenile systemic lupus erythematosus
}

\author{
Waleed Hassan ${ }^{1}(\mathbb{D})$ Eman Behiry² (D), Marwa Mahgoub ${ }^{1}(\mathbb{D}$ \\ ${ }^{1}$ Department of Rheumatology and Rehabilitation, Benha University, Faculty of Medicine, Benha, Egypt \\ ${ }^{2}$ Department of Clinical and Chemical Pathology, Benha University, Faculty of Medicine, Benha, Egypt
}

\begin{abstract}
Objectives: This study aims to assess the urinary soluble alpha chain of the interleukin-2 receptor (sCD25) concentrations in patients with juvenile systemic lupus erythematosus (JSLE) and to evaluate its validity to be a possible marker of disease activity in patients with lupus nephritis (LN).

Patients and methods: We assessed SCD25 concentrations in urine samples obtained from 53 JSLE patients (15 males, 38 females; median age 11 years; range, 7 to 17 years) and 30 age- and sex-matched apparently healthy controls (10 males, 20 females; median age 10 years; range, 6 to 16 years). Concentrations were normalized according to urinary creatinine excretion. JSLE patients were subjected to clinical examination and assessment of overall disease activity by Systemic Lupus Erythematous Disease Activity Index (SLEDAI), while evaluation of LN activity was preformed using Systemic Lupus International Collaborating Clinics (SLICC) renal activity score.

Results: The JSLE patients had significantly higher normalized urinary $\mathrm{sCD} 25$ concentrations compared to the healthy controls ( $p=0.001)$. Patients with active LN had significantly higher normalized urinary SCD25 levels than active JSLE patients without LN $(p=0.002)$ and JSLE patients with inactive disease $(p<0.001)$. A significant positive correlation was found between normalized urinary sCD25 concentrations with different activity parameters such as proteinuria $(p=0.004)$, SLEDAI $(p<0.001)$, renal SLEDAI $(p<0.001)$, and SLICC renal activity score $(p<0.001)$. A significant negative correlation was found between urinary sCD25 and complement $3(p<0.001)$.

Conclusion: Urinary concentrations of SCD25 were significantly elevated in JSLE patients, particularly in those with active LN. The remarkable association between urinary sCD25 concentrations and different renal disease activity parameters implies that urinary sCD25 can be a beneficial marker to monitor active nephritis in JSLE patients.

Keywords: Juvenile systemic lupus erythematosus, lupus nephritis, nephritis activity, urinary alpha chain of the interleukin-2 receptor.
\end{abstract}

Systemic lupus erythematosus (SLE) is a multisystemic, chronic inflammatory, autoimmune disease resulting from genetic predisposition, autoimmunity, and triggered by environmental factors. ${ }^{1,2}$ Lupus nephritis (LN) is a severe impact of SLE that predisposes to higher morbidity and mortality rates. ${ }^{3}$

Juvenile SLE (JSLE) has a worse outcome than its adult equivalent. ${ }^{4}$ The higher incidence of nephritis and neurological involvement usually leads to a tragic end. ${ }^{5-7}$ Early diagnosis and proper management diminish organ damage, renal failure, and improves age expectancy. ${ }^{8}$ Renal biopsy is the most specific modality for LN diagnosis, activity and chronicity assessment, and treatment feedbacks. Being an invasive procedure, it is not an easily acceptable method for many patients, which urges the research to find new predictable biomarkers. ${ }^{9,10}$ The conventional biomarkers

Received: January 04, 2020 Accepted: February 17, 2020 Published online: June 26, 2020

Correspondence: Marwa Mahgoub, MD. Department of Rheumatology and Rehabilitation, Benha University, Faculty of Medicine, 13511 Benha, Egypt. Tel: +20 133232679 e-mail: marwa.yahia@fmed.bu.edu.eg

Citation:

Hassan W, Behiry E, Mahgoub M. Urinary soluble alpha chain of the interleukin-2 receptor as a biomarker of active lupus nephritis in Egyptian children with juvenile systemic lupus erythematosus. Arch Rheumatol 2021;36(1):47-55.

This is an open access article under the terms of the Creative Commons Attribution-NonCommercial License. which permits use. distribution and reproduction in any medium. provided the original work is properly cited and is not used for commercial purposes (http://creativecommons.org/licenses/by-nc/4.0/). 
used for LN [proteinuria, anti-double stranded deoxyribonucleic acid antibodies (anti-dsDNA), complement (C) 3 and $\mathrm{C} 4$ levels] cannot imitate the real-time renal pathological changes..11,12 Biologic, genetic, and chemical characteristic biomarkers are currently studied to detect LN and its flare. ${ }^{13-15}$

Recently, biomarkers related to $\mathrm{T}$ cells have been focused in research due to the dominant role of $\mathrm{T}$ cells in $\mathrm{LN}$ pathogenesis. They trigger nephritogenic autoantibodies production by $\mathrm{B}$ cells, modulate the function of helper and effector $\mathrm{T}$ cells, and regulate $\mathrm{B}$ cell responses. ${ }^{16}$

The alpha chain of the interleukin-2 receptor (CD25) is located in the surface of $\mathrm{T}$ cells. Its soluble form $(\mathrm{sCD} 25)$ is produced by the proteolytic cleavage of interleukin 2 receptor (IL-2R) subunit alpha from cell membrane, which follows activation of mononuclear cells. It was detected to be a marker of $\mathrm{T}$ cell activation. Its earlier expression is usually detected prior to lymphocyte proliferation or other cell surface activity determinants while its higher levels in serum and urine give it the strength to be a good predictor of autoimmunity. ${ }^{17-19}$

Detection of serum ${ }^{20,21}$ and urinary ${ }^{22,23} \mathrm{sCD} 25$ were reported to be sensitive and specific for adult LN activity. It is easier to obtain urine than blood samples from children. ${ }^{24}$ Thus, in this study, we aimed to assess the urinary sCD25 concentrations in patients with JSLE and to evaluate its validity to be a possible marker of disease activity in patients with LN.

\section{PATIENTS AND METHODS}

This case-control study was conducted at the Pediatric Rheumatology Outpatient Clinic of the Rheumatology and Rehabilitation Department of Benha University and the Children's Hospital between November 2016 and December 2017. The study included 53 patients with JSLE (15 males, 38 females; median age: 11 years; range, 7 to 17 years) who were diagnosed using the Systemic Lupus International Collaborating Clinics (SLICC) classification criteria for $\mathrm{SLE}^{25}$ and 30 age- and sex-matched apparently healthy controls (10 males, 20 females; median age: 10 years; range, 6 to 16 years). Patients with another autoimmune disease, recent infection or end-stage renal disease were excluded. The study protocol was approved by the Benha University Research Ethics Committee. A written informed consent was obtained from the legal guardian of each participant. The study was conducted in accordance with the principles of the Declaration of Helsinki.

The JSLE patients underwent detailed history taking and clinical evaluation. Disease activity was assessed with the Systemic Lupus Erythematous Disease Activity Index 2000 (SLEDAI-2k); active disease was considered for scores $\geq 6$. $^{26} \mathrm{LN}$ activity was evaluated using the renal component of SLEDAI-2k (rSLEDAI) ranging from 0 to 16 and SLICC renal activity score $^{27}$ ranging from 0 to 15 ; active $\mathrm{LN}$ was considered for rSLEDAI $>4 .{ }^{28}$

The patients were grouped as JSLE with active LN ( $\mathrm{n}=16)$, active JSLE without LN ( $\mathrm{n}=17)$, and JSLE with inactive disease $(n=20)$. Organ damage in JSLE patients was evaluated using SLICC/American College of Rheumatology damage index (SDI) ${ }^{29}$ and renal biopsy was obtained from patients with active $\mathrm{LN}$ and assessed using the classification system of the 2003 revised International Society of Nephrology/Renal Pathology Society (ISN/RPS). ${ }^{30}$

Six milliliter of blood was aspirated from each participant and divided into three parts: first part placed in citrated tube to assess the erythrocyte sedimentation rate (ESR), second part of $1 \mathrm{~mL}$ placed in $150 \mu \mathrm{L}$ ethylenediaminetetraacetic acid to perform complete blood counting (CBC), and third part placed in an empty test tube (without anticoagulant), kept at room temperature for $30 \mathrm{~min}$ to coagulate, centrifuged at $1500 \mathrm{rpm}$ for $15 \mathrm{~min}$ and the separated serum collected for assessment of C-reactive protein (CRP), C3, C4, anti-dsDNA, serum urea, and creatinine.

Urine samples were obtained in conjunction with serum sampling of creatinine for evaluation of $\mathrm{sCD} 25$, proteinuria, and urine creatinine level. Urine specimens were collected through $24 \mathrm{~h}$ and the extracted urine was centrifuged for $10 \mathrm{~min}$ and preserved at $-40{ }^{\circ} \mathrm{C}$ till used for the assessment of sCD25 and creatinine. 
Table 1. Characteristics of juvenile systemic lupus erythematosus patients and healthy controls

\begin{tabular}{|c|c|c|c|c|c|c|c|c|c|c|c|}
\hline & \multicolumn{5}{|c|}{ JSLE patients $(\mathrm{n}=53$ ) } & \multicolumn{5}{|c|}{ Controls $(n=30)$} & \multirow[b]{2}{*}{$p$} \\
\hline & $\mathrm{n}$ & $\%$ & Mean \pm SD & Median & Range & $\mathrm{n}$ & $\%$ & Mean \pm SD & Median & Range & \\
\hline Age (year) & & & & 11 & $7-17$ & & & & 10 & $6-16$ & 0.3 \\
\hline $\begin{array}{l}\text { Sex } \\
\text { Female } \\
\text { Male }\end{array}$ & $\begin{array}{l}38 \\
15\end{array}$ & & & & & $\begin{array}{l}20 \\
10\end{array}$ & & & & & 0.82 \\
\hline Body mass index $\left(\mathrm{kg} / \mathrm{m}^{2}\right)$ & & & $20.9 \pm 3.2$ & & & & & $19.7 \pm 3.1$ & & & 0.09 \\
\hline Disease duration (months) & & & & 12 & $2-52$ & & & & NA & NA & - \\
\hline Cutaneous involvement & 31 & 58.5 & & & & NA & NA & & & & - \\
\hline Musculoskeletal involvement & 33 & 62.3 & & & & NA & NA & & & & - \\
\hline Hypertension & 14 & 26.4 & & & & NA & NA & & & & - \\
\hline Active nephritis & 16 & 30.2 & & & & NA & NA & & & & - \\
\hline Neurological involvement & 13 & 24.5 & & & & NA & NA & & & & - \\
\hline Leucopenia & 21 & 39.6 & & & & NA & NA & & & & - \\
\hline Thrombocytopenia & 16 & 30.2 & & & & NA & NA & & & & - \\
\hline Cardiac involvement & 8 & 5.1 & & & & NA & NA & & & & - \\
\hline $\operatorname{ESR}\left(\mathrm{mm} / 1^{\text {st }} \mathrm{h}\right)$ & & & & 28 & $7-113$ & & & & NA & NA & - \\
\hline $\mathrm{CRP}(\mathrm{mg} / \mathrm{L})$ & & & & 8.7 & $2.3-96.3$ & & & & NA & NA & - \\
\hline Hemoglobin (gm/dL) & & & $10.6 \pm 1.4$ & & & & & NA & & & - \\
\hline WBCs $\left(10^{3} / \mathrm{cmm}\right)$ & & & $5.6 \pm 2.7$ & & & & & NA & & & - \\
\hline Platelets $\left(10^{3} / \mathrm{cmm}\right)$ & & & $232.8 \pm 95.1$ & & & & & & & & - \\
\hline Proteinuria (gm/24 h urine) & & & & 0.24 & $0.02-6.3$ & & & & NA & NA & - \\
\hline Serum creatinine (mg/dL) & & & & 0.7 & $0.45-3.8$ & & & & NA & NA & - \\
\hline Blood urea (mg/dL) & & & & 17 & $14-132$ & & & & NA & NA & - \\
\hline eGFR (mL/min/1.73 m²) & & & $78.7 \pm 29.3$ & & & & & NA & & & - \\
\hline C3 (mg/dL) & & & & 104.74 & $43-165$ & & & & NA & NA & - \\
\hline $\mathrm{C} 4(\mathrm{mg} / \mathrm{dL})$ & & & & 14.79 & $4.4-32.4$ & & & & NA & NA & - \\
\hline Anti-dsDNA (IU/mL) & 27 & 51 & & & & NA & NA & & & & - \\
\hline Normalized Ur sCD25 (pg/mg) & & & & 243 & $100-655$ & & & & 159.5 & $74-423$ & $0.001^{*}$ \\
\hline SLEDAI-2k & & & & 9 & 0-33 & & & & NA & NA & - \\
\hline Renal SLEDAI & & & & 0 & $0-16$ & & & & NA & NA & - \\
\hline SLICC renal activity score & & & & 0 & $0-15$ & & & & NA & NA & - \\
\hline SDI & & & & 2 & $0-7$ & & & & NA & NA & - \\
\hline
\end{tabular}

The $\mathrm{CBC}$ was performed for all samples using Sysmex XP-300 (Sysmex Corporation, New York, USA). ESR was evaluated by the Westergren method. Quantitative CRP (BioSystems S.A., Barcelona, Spain) was assessed by the turbidimetry method.

The resultant serum was used for renal function tests. Serum and urine creatinine were measured using the BioSystems reagent kit of the BioSystems S.A. Serum urea was measured via applying the enzymatic colorimetric test (Diamond Diagnostics, Holliston, MA, USA), performed by Biosystem BTS 350 Semiautomatic analyzer (Biosystems, Spain). Estimated creatinine clearance was measured by the Schwartz formula. ${ }^{31}$

Reagents from Far Diagnostics (Verona, Italy) were purchased to assay C3 and C4 applying radial immunodiffusion plate. Twenty-four-hour urine protein was measured by turbidimetry method using trichloroacetic acid with BioSystems BTS-350 spectrophotometer device. Anti-dsDNA was detected by indirect immunofluorescence by Inova Diagnostics (San Diego, USA).

Urinary sCD25 was conducted using enzymelinked immunosorbent assay kit (SunRed Biotech, Shanghai, China) with catalog number: 
201-12-5522. Results of urinary sCD25 were normalized to creatinine in each participant.

\section{Statistical analysis}

Data analyses were performed using the IBM SPSS version 20.0 software (IBM Corp., Armonk, NY, USA). Mean and standard deviation were used to present normally distributed data while median and range were used for non-parametric data. A comparison between parametric data was performed by t-test and one-way analysis of variance. Comparison between normalized urinary sCD25 concentrations in JSLE patients and the controls was performed using the MannWhitney $U$ test. Also, Kruskal-Wallis test was selected to compare the non-parametric data between more than two groups. The linear association between normalized urinary sCD25 and different disease variables was tested using the Spearman's correlation coefficient. The diagnostic performance of normalized urinary sCD25 in predicting SLEDAI score and its renal component was tested using the receiver operating characteristics (ROC) curve.

\section{RESULTS}

Cutaneous manifestations were found in 31 (58\%) JSLE patients in the form of malar rash, photosensitivity, and hair loss. Musculoskeletal manifestations included arthralgia, arthritis, and

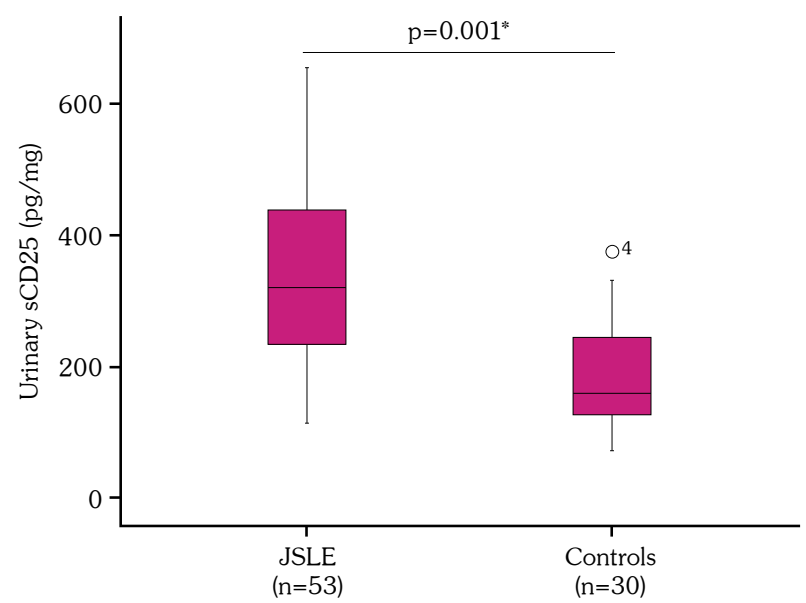

Figure 1. Comparison of normalized urinary sCD25 levels between JSLE patients and healthy controls.

JSLE: Juvenile systemic lupus erythematosus; $\mathrm{sCD} 25$ : Soluble alpha chain of interleukin-2 receptor. myalgia in 33 (62.3\%) patients. Also, neurological involvement was found in $13(24.5 \%)$ patients in the form of seizures, headache, psychosis, and cerebrovascular accident. The baseline features of JSLE patients and the controls were shown in Table 1.

All our JSLE patients were receiving variable doses of prednisone, 49 (92.45\%) patients were receiving hydroxychloroquine, 24 (45.28\%) azathioprine, 15 (33.4\%) mycophenolate mofetil, and 10 (13.2\%) cyclophosphamide intravenous infusion.

In JSLE patients, normalized urinary sCD25 concentrations (median 243; range, 100 to $655 \mathrm{pg} / \mathrm{mg}$ ) were significantly higher $(p=0.001)$ than their normalized urinary concentrations in healthy controls (median 159.5; range, 74 to $423 \mathrm{pg} / \mathrm{mg}$ ) (Figure 1). Furthermore, normalized urinary concentrations of sCD25 in JSLE patients with active LN $(402.7 \pm 139.6 \mathrm{pg} / \mathrm{mg})$ were significantly higher compared to normalized urinary concentrations in active JSLE patients without LN $(262.2 \pm 98.4 \mathrm{pg} / \mathrm{mg}$, $\mathrm{p}=0.002)$ and JSLE patients with inactive disease $(192.7 \pm 66.4 \mathrm{pg} / \mathrm{mg}, \mathrm{p}<0.001)$. Also, active JSLE patients without LN $(n=17)$ had significantly higher normalized urinary concentrations of sCD25 than normalized urinary concentrations in JSLE patients with inactive disease $(n=20, p=0.015)$ (Figure 2).

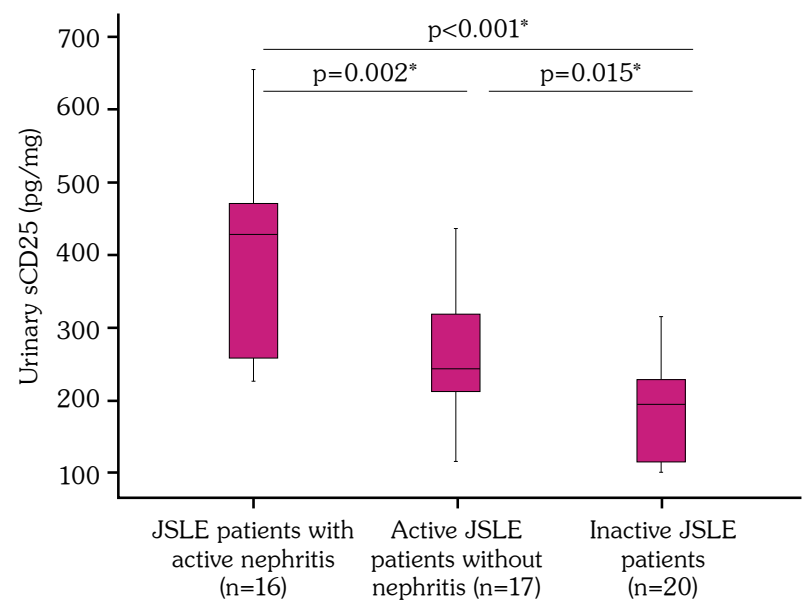

Figure 2. Comparison of normalized urinary sCD25 levels between JSLE patients with active nephritis, active JSLE patients without nephritis and inactive JSLE patients.

JSLE: Juvenile systemic lupus erythematosus; $\mathrm{SCD} 25$ : Soluble alpha chain of interleukin-2 receptor. 


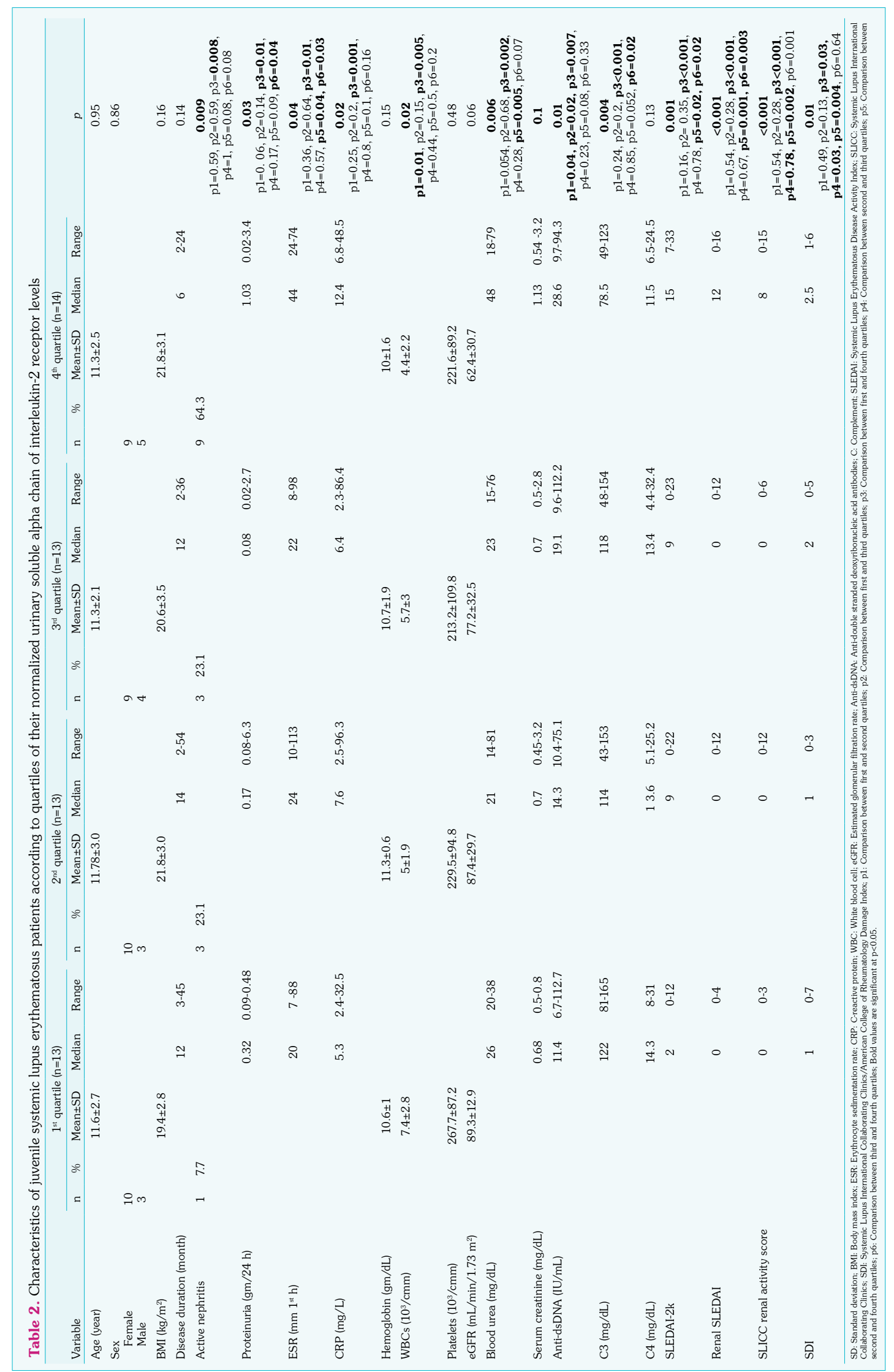


Table 3. Correlation between normalized urinary soluble alpha chain of interleukin-2 receptor levels and different parameters in juvenile systemic lupus erythematosus patients

\begin{tabular}{|c|c|c|}
\hline \multirow[b]{2}{*}{ Parameter } & \multicolumn{2}{|c|}{$\begin{array}{l}\text { Normalized urinary } \\
\text { sCD25 }\end{array}$} \\
\hline & $\mathrm{r}$ & $\mathrm{p}$ \\
\hline Age & -0.1 & 0.46 \\
\hline Disease duration & -0.2 & 0.15 \\
\hline Body mass index & 0.15 & 0.28 \\
\hline Erythrocyte sedimentation rate & 0.13 & 0.34 \\
\hline C-reactive protein & 0.07 & 0.64 \\
\hline Hemoglobin & -0.23 & 0.1 \\
\hline White blood cells & -0.24 & 0.08 \\
\hline Platelets & -0.11 & 0.43 \\
\hline Proteinuria & 0.39 & 0.004 \\
\hline Blood urea & 0.25 & 0.07 \\
\hline Creatinine & 0.16 & 0.26 \\
\hline Estimated glomerular filtration rate & -0.26 & 0.06 \\
\hline Complement 3 & -0.48 & $<0.001$ \\
\hline Complement 4 & -0.16 & 0.26 \\
\hline Anti-dsDNA & 0.12 & 0.38 \\
\hline SLEDAI-2k & 0.48 & $<0.001$ \\
\hline Renal SLEDAI & 0.61 & $<0.001$ \\
\hline SLICC renal activity score & 0.68 & $<0.001$ \\
\hline SDI & 0.21 & 0.13 \\
\hline Renal biopsy activity index & 0.62 & 0.01 \\
\hline Renal biopsy chronicity index & -0.19 & 0.48 \\
\hline \multicolumn{3}{|c|}{$\begin{array}{l}\text { sCD25: Soluble alpha chain of interleukin-2 receptor; Anti-dsDNA: Anti- } \\
\text { double stranded deoxyribonucleic acid antibodies; SLEDAI: Systemic Lupus } \\
\text { Erythematosus Disease Activity Index; SLICC: Systemic Lupus International } \\
\text { Collaborating Clinics; SDI: Systemic Lupus International Collaborating Clinics/ } \\
\text { American College of Rheumatology Damage Index. }\end{array}$} \\
\hline
\end{tabular}

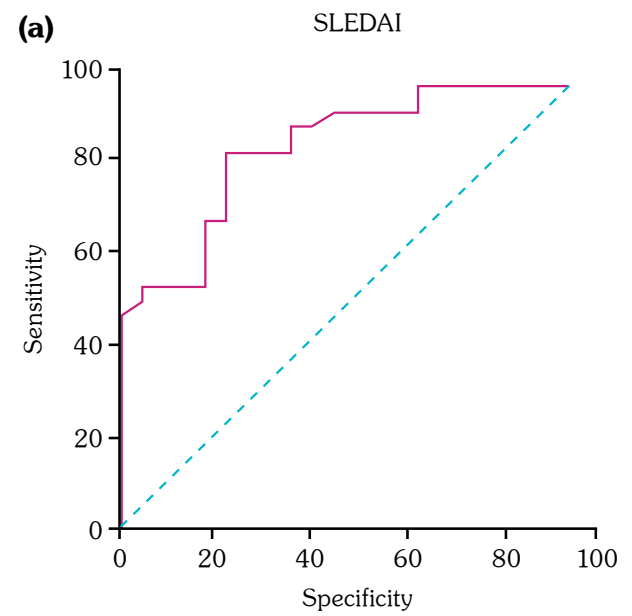

Regarding renal biopsy, nine patients (59.25\%) had biopsy Grade IV with a mean of their normalized urinary $\mathrm{sCD} 25$ of $419.4 \pm 134.1 \mathrm{pg} / \mathrm{mg}$, four (25\%) had biopsy Grade III with a mean of their normalized urinary sCD25 of $411.8 \pm 194.4 \mathrm{pg} / \mathrm{mg}$, two (12.5\%) had biopsy grade $\mathrm{V}$ with a mean of their normalized urinary $\mathrm{sCD} 25334.5 \pm 142.1 \mathrm{pg} / \mathrm{mg}$, and only one patient (6.25\%) had biopsy Grade II with a normalized urinary sCD25 of $352 \mathrm{pg} / \mathrm{mg}$.

The JSLE patients were categorized into quartiles according to their normalized urinary sCD25 levels. Patients with the highest (fourth) quartile of normalized urinary sCD25 showed significantly higher prevalence of active nephritis, ESR, CRP, proteinuria, anti-dsDNA, urea, SLEDAI-2k, rSLEDAI, SLICC renal activity score, and SDI while lower C3. Characteristics of JSLE patients according to quartiles of their normalized urinary $\mathrm{sCD} 25$ were presented in Table 2.

Normalized urinary sCD25 levels showed a positive significant correlation with proteinuria $(\mathrm{r}=0.39, \mathrm{p}=0.004)$ SLEDAI $(\mathrm{r}=0.48, \mathrm{p}<0.001)$, rSLEDAI $(r=0.61, p<0.001)$, SLICC renal activity score $(r=0.68, p<0.001)$, and renal biopsy activity index $(r=0.62, p=0.01)$ while a negative significant correlation was established between normalized urinary sCD25 concentrations and C3 $(r=-0.48$, $\mathrm{p}<0.001$ ) (Table 3).

Figure 3 shows the ROC curve analysis of the diagnostic performance of normalized

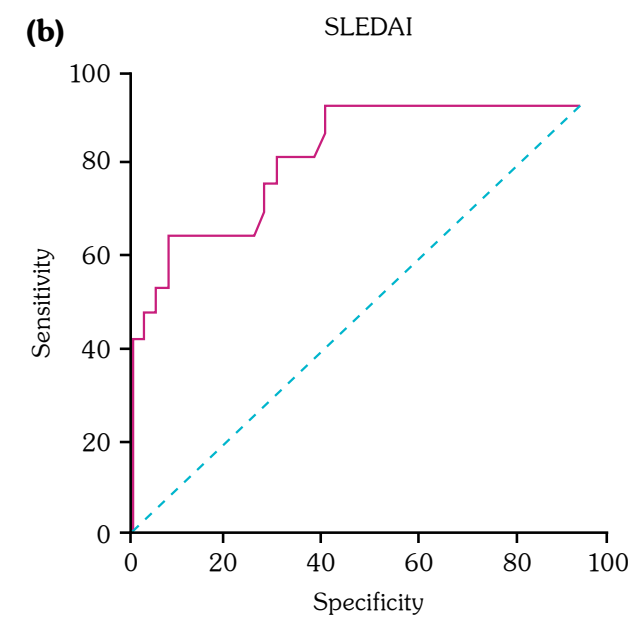

Figure 3. ROC curve analysis of the diagnostic performance normalized urinary sCD25 in predicting disease activity using SLEDAI (a) and its renal component (b).

SLEDAI: Systemic Lupus Erythematosus Disease Activity Index. 
urinary sCD25 levels in predicting disease activity using SLEDAI and its renal related component (rSLEDAI). Regarding SLEDAI, urinary sCD25 had an AUC of 0.85 at a cut-off point of $218 \mathrm{pg} / \mathrm{mg}$ with $84.4 \%$ sensitivity and $76.2 \%$ specificity (Figure 3a). While for rSLEDAI, urinary sCD25 had an AUC of 0.88 at a cut-off point of $324 \mathrm{pg} / \mathrm{mg}$ with $68.7 \%$ sensitivity and $91.9 \%$ specificity (Figure $3 b$ ).

\section{DISCUSSION}

Juvenile SLE is an autoimmune disease that, although being uncommon, is considered a critical condition. ${ }^{20}$ Renal involvement is a frequent finding in JSLE patients and it usually leads to increased mortality rate if not probably diagnosed and treated. ${ }^{21}$ Early diagnosis is the target of recent researches. Soluble CD25 is a new biomarker that has been studied in LN and was proven to have a role in $\mathrm{LN}$ pathogenesis and activity. ${ }^{20-23}$

This study demonstrated the correlations between urinary sCD25 and different activity parameters among our JSLE patients that were more obvious in those with LN. We found that the normalized urinary sCD25 levels were elevated in JSLE patients than controls. It is worth to note that active JSLE patients without LN had a significant increase in their normalized urinary sCD25 levels than those in remission. Gupta et al. ${ }^{22}$ reported similar outcomes with a remarkable correlation between urinary sCD25 and SLEDAI. On the other hand, Wong and Wong ${ }^{32}$ did not approve this association.

Overall, normalized urinary sCD25 concentrations significantly correlated with activity parameters including SLEDAI, renal SLEDAI, SLICC renal activity score, and C3 in all JSLE patients. Although SLE disease is characterized by $\mathrm{B}$ cell hyperactivity with subsequent profound release of autoantibodies, $\mathrm{T}$ cell activation has been proven to be the central initiating signal in this autoimmunity process. ${ }^{33} \mathrm{sCD} 25$ represents the alpha chain of the IL-2 receptor and has been suggested to be the most prominent marker of cellular activation. Numerous cytokines that trigger $\mathrm{T}$ cell activation can induce CD25 expression. ${ }^{34}$
Strikingly, we found that the normalized urinary sCD25 concentrations were higher in JSLE patients with active LN than in those with inactive disease. Moreover, the active LN patients showed higher levels than active JSLE patients without $\mathrm{LN}$ with a significant correlation between urinary sCD25 concentrations and renal biopsy activity indices.

Several previous studies reported that the kidney invasion by $\mathrm{T}$ cells particularly activated cluster of differentiation 4 early in LN pathogenesis. ${ }^{33} \mathrm{~T}$ cells have a notable role in $\mathrm{LN}$ by helping $\mathrm{B}$ cell production of nephritogenic autoantibodies. ${ }^{16}$ High sCD25 concentration represents increased $\mathrm{T}$ cell activation and migration of $\mathrm{T}$ cells and might echo the early stage of LN. ${ }^{22,35}$

Our patients' data of the positive correlation between urinary sCD25 levels with different parameters of LN activity were in line with those of Gupta et al. ${ }^{22}$ who reported increased urinary sCD25 levels in their active LN patients compared to controls and patients with inactive disease and concluded that it is a sensitive follow-up marker for relapse and poor response of LN. Yet, they found no significant difference regarding urinary sCD25 between SLE patients with and without active LN. Furthermore, they could not establish any significant association between urinary sCD25 levels and their combined serum sCD25 levels. Their findings emphasized the suggestion of Tsai et al., ${ }^{36}$ regarding local $\mathrm{T}$ cell activation in LN patients' renal tissues in the beginning of $\mathrm{LN}$ activity.

Additionally, our patients with the highest (fourth) quartile of normalized urinary sCD25 showed significantly higher prevalence of active nephritis and elevated levels of ESR, CRP, proteinuria, anti-ds-DNA, SLEDAI-2k, rSLEDAI, and SLICC renal activity score and more interestingly organ damage measured with SDI. Although we found that the urinary sCD25 levels were higher in patients who had biopsy Grade III and IV (severe inflammation and more $T$ cell activation), we could not test the significance of this difference due to the small number of other biopsy grades. These results may confirm the relationship between the concurrent immune activation in the kidney and urinary sCD25. 
Many studies evaluated the relationship between serum ${ }^{20,21}$ and urinary ${ }^{22,23,36}$ sCD25 levels in adult-onset SLE patients while only one study tested this relationship in JSLE patients, ${ }^{37}$ suggesting that $\mathrm{sCD} 25$ is a sensitive marker of $\mathrm{LN} .{ }^{21,23}$ However, none of them tested the relationship of urinary $\mathrm{sCD} 25$ and organ damage as a measure of severity of SLE.

Our limitations lie in the relatively small sample size particularly in those with renal biopsy, lack of serum sCD25 levels and their correlation with urinary levels, lack of an expression study of CD25 in the tissue of renal biopsy, and lack of longitudinal follow-up of urinary sCD25 after treatment of active patients to test the effect of various treatment lines on sCD25 urinary levels.

In conclusion, urinary sCD25 levels are significantly increased in JSLE patients, particularly in those with active nephritis that remarkably correlated with different inflammatory and activity parameters suggesting that urinary sCD25 can be a valuable biomarker of JSLE disease activity. The considerable association between elevated urinary sCD25 and SLE damage index implies a possible prognostic role in JSLE patients.

\section{Declaration of conflicting interests}

The authors declared no conflicts of interest with respect to the authorship and/or publication of this article.

\section{Funding}

The authors received no financial support for the research and/or authorship of this article.

\section{REFERENCES}

1. Harley IT, Kaufman KM, Langefeld CD, Harley JB, Kelly JA. Genetic susceptibility to SLE: new insights from fine mapping and genome-wide association studies. Nat Rev Genet 2009;10:285-90.

2. Prokunina L, Alarcon-Riquelme M. The genetic basis of systemic lupus erythematosus--knowledge of today and thoughts for tomorrow. Hum Mol Genet 2004;13:R143-8.

3. Ward MM. Recent clinical trials in lupus nephritis. Rheum Dis Clin North Am 2014;40:519-35.

4. Malattia C, Martini A. Paediatric-onset systemic lupus erythematosus. Best Pract Res Clin Rheumatol 2013;27:351-62.
5. Lewandowski LB, Schanberg LE, Thielman N, Phuti A, Kalla AA, Okpechi I, et al. Severe disease presentation and poor outcomes among pediatric systemic lupus erythematosus patients in South Africa. Lupus 2017;26:186-94.

6. Baştuğ F, Poyrazoglu H, Gunduz Z, Tulpar S, Dusunsel R. Juvenile lupus erythematosus: fourteen years of experience. Turk J Rheumatol 2011;26:308-15.

7. Alyasin S, Amin R, Moghtaderi M, Kashef S. Childhood-onset systemic lupus erythematosus in southwestern iran: a clinical and serological study. Arch Rheumatol 2014;29:167-70.

8. Fiehn C, Hajjar Y, Mueller K, Waldherr R, Ho AD, Andrassy K. Improved clinical outcome of lupus nephritis during the past decade: importance of early diagnosis and treatment. Ann Rheum Dis 2003;62:435-9.

9. Bennett MR, Ma Q, Ying J, Devarajan P, Brunner $\mathrm{H}$. Effects of age and gender on reference levels of biomarkers comprising the pediatric Renal Activity Index for Lupus Nephritis (p-RAIL). Pediatr Rheumatol Online J 2017;15:74.

10. Schwartz N, Goilav B, Putterman C. The pathogenesis, diagnosis and treatment of lupus nephritis. Curr Opin Rheumatol 2014;26:502-9.

11. Wu $\mathrm{H}$, Zeng J, Yin J, Peng Q, Zhao M, Lu Q. Organ-specific biomarkers in lupus. Autoimmun Rev 2017;16:391-7.

12. Hsieh SC, Tsai CY, Yu CL. Potential serum and urine biomarkers in patients with lupus nephritis and the unsolved problems. Open Access Rheumatol 2016;8:81-91.

13. Birmingham DJ, Merchant M, Waikar SS, Nagaraja $\mathrm{H}$, Klein JB, Rovin BH. Biomarkers of lupus nephritis histology and flare: deciphering the relevant amidst the noise. Nephrol Dial Transplant 2017;32:i71-i9.

14. El-Saadany HM, Amer WH, Khalil HS, Gaber RA, Elshweikh SA. Association of STAT4 polymorphism with susceptibility and severity of rheumatoid arthritis and systemic lupus erythematosus in Egyptian patients. Egypt Rheumatol 2016;38:21-7.

15. Dima A, Jurcut C, Balanescu P, Balanescu E, Badea C, Caraiola S, et al. Clinical significance of serum and urinary interleukin- 6 in systemic lupus erythematosus patients. Egypt Rheumatol 2017;39:1-6.

16. Hoffman RW. T cells in the pathogenesis of systemic lupus erythematosus. Clin Immunol 2004;113:4-13.

17. Rubin LA, Nelson DL. The soluble interleukin-2 receptor: biology, function, and clinical application. Ann Intern Med 1990;113:619-27.

18. Comte D, Karampetsou MP, Tsokos GC. T cells as a therapeutic target in SLE. Lupus 2015;24:351-63.

19. Luo H, Wang C, Feng M, Zhao Y. Microgravity inhibits resting $\mathrm{T}$ cell immunity in an exposure timedependent manner. Int J Med Sci 2013;11:87-96.

20. El-Shafey EM, El-Nagar GF, El-Bendary AS, Sabry AA, Selim AG. Serum soluble interleukin-2 receptor 
alpha in systemic lupus erythematosus. Iran J Kidney Dis 2008;2:80-5.

21. Zhang RJ, Zhang X, Chen J, Shao M, Yang Y, Balaubramaniam B, et al. Serum soluble CD25 as a risk factor of renal impairment in systemic lupus erythematosus - a prospective cohort study. Lupus 2018;27:1100-6.

22. Gupta R, Yadav A, Misra R, Aggarwal A. Urinary sCD25 as a biomarker of lupus nephritis disease activity. Lupus 2015;24:273-9.

23. Hussein Zeid MM, Baddour NM, El-Neily DAEM, Elshaira HS, Mamdouha M. Study of urinary interferon gamma-induced protein 10 (IP-10) and urinary soluble CD 25 (sCD25) as markers of lupus nephritis and their relation to histological class. Alexandria J Med 2018;54:647-53.

24. Chen Y, Qian H and Shi G. Advances in Study of Biomarkers for Lupus Nephritis. Austin J Clin Immunol 2018;5:1033.

25. Petri M, Orbai AM, Alarcón GS, Gordon C, Merrill JT, Fortin PR, et al. Derivation and validation of the Systemic Lupus International Collaborating Clinics classification criteria for systemic lupus erythematosus. Arthritis Rheum 2012;64:2677-86.

26. Gladman DD, Ibañez D, Urowitz MB. Systemic lupus erythematosus disease activity index 2000. J Rheumatol 2002;29:288-91.

27. Petri M, Kasitanon N, Lee SS, Link K, Magder L, Bae $\mathrm{SC}$, et al. Systemic lupus international collaborating clinics renal activity/response exercise: development of a renal activity score and renal response index. Arthritis Rheum 2008;58:1784-8.

28. Xuejing $Z$, Jiazhen T, Jun L, Xiangqing $X$, Shuguang $Y$, Fuyou L. Urinary TWEAK level as a marker of lupus nephritis activity in 46 cases. J Biomed Biotechnol 2012;2012:359647.

29. Gladman D, Ginzler E, Goldsmith C, Fortin P, Liang M,
Urowitz M, et al. The development and initial validation of the Systemic Lupus International Collaborating Clinics/American College of Rheumatology damage index for systemic lupus erythematosus. Arthritis Rheum 1996;39:363-9.

30. Weening JJ, D'Agati VD, Schwartz MM, Seshan SV, Alpers CE, Appel GB, et al. The classification of glomerulonephritis in systemic lupus erythematosus revisited. Kidney Int 2004;65:521-30.

31. Schwartz GJ, Brion LP, Spitzer A. The use of plasma creatinine concentration for estimating glomerular filtration rate in infants, children, and adolescents. Pediatr Clin North Am 1987;34:571-90.

32. Wong KL, Wong RP. Serum soluble interleukin 2 receptor in systemic lupus erythematosus: effects of disease activity and infection. Ann Rheum Dis 1991;50:706-9.

33. Foster MH. T cells and B cells in lupus nephritis. Semin Nephrol 2007;27:47-58.

34. Hosono M, de Boer OJ, van der Wal AC, van der Loos CM, Teeling P, Piek JJ, et al. Increased expression of T cell activation markers (CD25, CD26, CD40L and CD69) in atherectomy specimens of patients with unstable angina and acute myocardial infarction. Atherosclerosis 2003;168:73-80.

35. Jackson AL, Matsumoto $H$, Janszen M, Maino V, Blidy A, Shye S. Restricted expression of p55 interleukin 2 receptor (CD25) on normal T cells. Clin Immunol Immunopathol 1990;54:126-33.

36. Tsai CY, Wu TH, Sun KH, Lin WM, Yu CL. Increased excretion of soluble interleukin 2 receptors and free light chain immunoglobulins in the urine of patients with active lupus nephritis. Ann Rheum Dis 1992;51:168-72.

37. Salam M, Tawfeek DM, Mobasher ES, Khalifa NA, El Shafaei M. Urinary CD25 as a Biomarker of Lupus Nephritis Activity in Pediatrics. Geget 2019;14: 82-9. 